\title{
A definição de trabalho social da FITS: Por que revisar?
}

The IFSW social work definition: Why should it be reviewed?

Conselho Federal de Serviço Social*

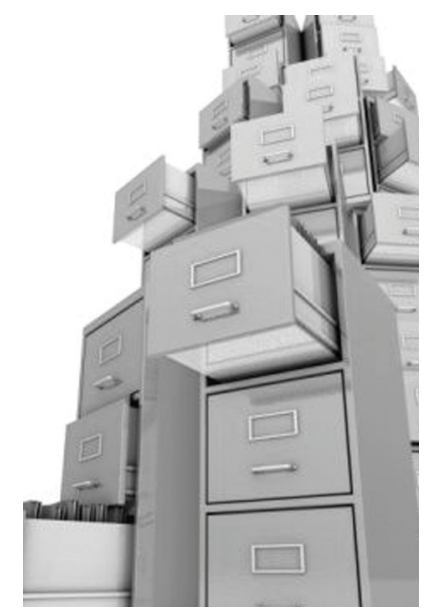

Resumo: O texto que segue trata do debate brasileiro sobre a definição de Serviço Social aprovada pela Federação Internacional de Trabalhadores Sociais - Fits na assembleia de Montreal, Canadá, no ano 2000. Na assembleia de Hong Kong, em 2010, a proposta de realização de um workshop no Brasil sobre o tema foi aprovada como estratégia da contribuição latino-americana no processo de sua revisão. Este tema será discutido na próxima assembleia da Fits em Estocolmo, de 8 a 12 de julho de 2012.

Palavras-chave: Serviço Social. Fits. América Latina.

\begin{abstract}
The following text is about the Brazilian debate on the definition of Social Service approved by the International Federation of Social Workers - IFSW - in the Assembly in Montreal, Canada, in 2000. In the Assembly in Hong Kong in 2010, the proposal of a workshop on the theme in Brazil was approved as a strategy of the Latin American contribution for its review. That theme will be discussed in the next IFSW assembly in Stockholm, from July $8^{\text {th }}$ to $12^{\text {th }}, 2012$.
\end{abstract}

Keywords: Social work. IFSW. Latin America.

\footnotetext{
* Conselho Federal de Serviço Social - CFESS. Gestão “Tempo de Luta e Resistência” 2011-2014. $<$ www.cfess.org.br>.E-mail: cfess@cfess.org.br.
} 


\section{Histórico e Posição do CFESS sobre a Definição Mundial de Trabalho Social da FITS 1}

$\mathrm{A}$

Federação Internacional de Trabalhadores Sociais (Fits), entidade que congrega as associações nacionais representativas de trabalhadores sociais e/ou assistentes sociais, e da qual o Conselho Federal de Serviço Social (Cfess) faz parte, adota uma definição de trabalho social que pretende ser uma expressão mundial do que é a profissão. Historicamente, esta definição é discutida e aprovada na assembleia da Fits, pelas associações filiadas presentes. A atual definição de trabalho social da Fits ${ }^{2}$ foi aprovada na assembleia realizada em Montreal, em 2000, e substituiu a definição existente desde 1982.

A posição defendida pelo CFESS e demais associações latino-americanas na assembleia foi contrária à existência de uma definição mundial com o objetivo de acumular maior discussão e criar maior consenso. Porém essa posição foi derrotada e a definição foi aprovada, com a indicação de sua revisão em dez anos. Contudo, a revisão não ocorreu na assembleia realizada em 2010, em Hong Kong. Continua na agenda da assembleia que acontecerá em Estocolmo, de 8 a 12 de julho de 2012. ${ }^{3}$

Como entidade representativa dos(as) assistentes sociais brasileiros(as), o CFESS é filiado à Fits e integra a diretoria da Federação. ${ }^{4} \mathrm{O}$ Brasil, em conjunto com as representações da América Latina, ${ }^{5}$ questiona a necessidade de existência de uma definição mundial, desde que passou a integrar a Fits em 2000, justamente por entender que os processos históricos de surgimento e desenvolvimento do Serviço Social em cada país são particulares, determinados pelas condições objetivas, políticas, econômicas e culturais em que se desenvolvem.

1. Não abordaremos neste texto a questão da distinção entre trabalho social e Serviço Social. Adotamos aqui o termo trabalho social como sinônimo de Serviço Social, por ser a terminologia adotada pela FITS e pela maioria dos países que a integra.

2. A definição vigente está disponível em vários idiomas na página eletrônica da FITS: <http://www. ifsw.org/f38000138.html>.

3. A convocatória e a programação encontra-se disponível em: $<$ http://www.swsd-stockholm-2012.org/> .

4. O CFESS integra a direção da Fits desde 2000. As representantes das últimas duas gestões são: Joaquina Barata Teixeira (2005-08) e Ivanete Boschetti (2008-12). A presidência regional da Fits para a América Latina e Caribe é exercida por Laura Acotto, da Argentina.

5. Cabe registrar que à época da aprovação da atual definição, o presidente regional para a América Latina e Caribe da Fits era Juan Manuel La Torre e, nesta assembleia da FITS, a posição dos países da América Latina foi contrária a sua aprovação. 
Em todos esses anos, o CFESS, junto com a atual presidência regional da Fits, seguiu defendendo, nas reuniões e assembleias, que a definição de uma profissão precisa ser situada e compreendida no processo histórico de constituição e desenvolvimento da profissão em cada país. Ademais, desde a sua aprovação, a definição não contou com a adesão de todos os países, excluindo mesmo um continente inteiro que nela não se viu representado, a América Latina. Daí a necessidade de sua revisão.

Desde 2006, a Fits e a Aiets constituíram um GT mundial com o objetivo de trabalhar na revisão e apresentar uma proposta na assembleia da Fits em Hong Kong, em 2010. Os países da América Latina e Caribe com representação na Fits (Argentina e Brasil) indicaram o professor José Paulo Netto para compor esse GT representando a região. O GT, contudo, nunca se reuniu, e durante a assembleia da Fits realizada em Salvador, em 2008, o professor José Paulo manteve o primeiro e único contato com o coordenador do GT pela Fits. Desde então, jamais foi contatado.

Na avaliação política do CFESS e da presidência regional da Fits para América Latina e Caribe, a não atuação do GT pode indicar uma postura de resistência à revisão da atual definição. Em virtude dessa avaliação, o CFESS atuou firmemente em defesa da revisão, adotando várias estratégias: pautou o assunto em todas as reuniões anuais da diretoria da FITS, desde a criação do GT, em 2006; pautou o debate nas reuniões do Comitê Mercosul e apresentou a proposta de elaboração de uma proposta conjunta dos países que o compõem; ${ }^{6}$ apresentou uma proposta de revisão parcial em alguns aspectos considerados mais problemáticos na atual definição, com o intuito estratégico de provocar o debate durante a Conferência Mundial e na assembleia da Fits ocorrida em Hong Kong, em 2010.

Essa proposta (Anexo 1) não alterava na essência a definição da Fits, mas se propunha a introduzir os princípios do Projeto Ético-Político Profissional e a assegurar um texto que tivesse apoio de outros países. ${ }^{7}$ O Conselho Pleno do CFESS, ao elaborar tal proposta, tinha absoluta clareza de que a mesma não expressava a riqueza, a profundidade e a perspectiva de totalidade do Serviço Social brasileiro, expresso no Projeto Ético-Político Profissional, contudo acreditava em seu potencial estratégico de mostrar aos países-membros da Fits que a atual definição estava longe de ser consensual. A avaliação política estava correta, pois a maioria dos

6. Infelizmente, por motivos alheios à atuação do CFESS, essa estratégia não pôde ser materializada.

7. A proposta foi traduzida para o espanhol e para o inglês, e 3 mil cópias impressas foram distribuídas durante a Conferência Mundial de Hong Kong. As versões em português, inglês e espanhol estão disponíveis na página eletrônica do CFESS: $<$ http://www.cfess.org.br/noticias_res.php?id=419>. 
países presentes na assembleia compreendeu a necessidade de revisar a atual definição e votou pela sua revisão em 2012. Os países mais resistentes à revisão da atual definição foram os da região da Ásia e a Áustria.

Para assegurar o debate no âmbito do GT mundial, o CFESS, com o apoio da presidência da Fits e da presidência regional da Fits para América Latina e Caribe, apresentou a proposta de realização de um workshop no Brasil para discutir a atual definição, encontrar pontos convergentes, que não firam os projetos profissionais dos países-membros da Fits. Essa tarefa, ainda que não seja fácil, é absolutamente viável.

A proposta foi aprovada na assembleia de 2010 e, desde então, o CFESS está em processo de organização do evento com previsão que seja realizado no primeiro semestre de 2012, antecedendo a Conferência Mundial de Estocolmo, Suécia.

O GT para organização do workshop vem se reunindo desde abril de 2011, e sua composição conta com representantes do CFESS/CRESSRJ, Abepss, Enesso, e de pesquisadores que vêm realizando o debate no âmbito do Serviço Social brasileiro. ${ }^{8}$ Além de contribuir com a organização do referido evento, o GT tem a incumbência de contribuir com a elaboração de uma proposta que cumpra a difícil tarefa de, ao mesmo tempo, manter-se fiel aos fundamentos e princípios do Projeto Ético-Político Profissional brasileiro e seja capaz de "envolver todos os mundos". Para tanto, o GT reunido em 13 de agosto de 2011 reelaborou a proposta apresentada pelo CFESS em Hong Kong (Anexo 2), com participação de Laura Acotto, presidente regional da Fits para América Latina e Caribe. O texto preliminar foi apresentado no $2^{\circ}$ Encuentro de Asociaciones de Trabajadores Sociales de La Región Latinoamericana y Caribeña da Fits e $27^{\mathrm{a}}$ Reunión del Comité Mercosur, realizado entre os dias 23 e 25 de agosto de 2011, em Mendoza, Argentina. Nesse encontro participaram organizações profissionais de trabalhadores sociais de dez países. $^{9}$ Deliberou-se que estas discutiriam com suas bases a proposta elaborada pelo GT brasileiro e iriam encaminhar sugestões para que fossem apresentadas no workshop, visando construir uma proposta comum da região. Nesse encontro tam-

8. Instituído pela Portaria CFESS n. 13/2011, o GT Ampliado é composto por conselheiros do CFESS: Samya Rodrigues Ramos, Esther Luíza de Souza Lemos, Maurílio Mattos e Marinete Cordeiro Moreira; do Cress/RJ com a conselheira Hilda Correa; a Abepss com Carlos Montaño e a Enesso por Wanderson Magalhães. Conta com participação de Joaquina Barata Teixeira, Ana Elizabete Mota, Valdete Barros Martins, Ivete Simionato, Silvana Mara Morais dos Santos, Elaine Rossetti Behring e Ivanete Boschetti, e tem como assessores os professores José Paulo Netto e Marilda Iamamoto.

9. Entre os países representados estavam: Argentina, Brasil, Chile, Colômbia, Nicarágua, Paraguai, Peru, Porto Rico, República Dominicana e Uruguai. 
bém foi deliberado que a próxima reunião do Comitê Mercosul de Organizações Profissionais de Trabalho Social será no Rio de Janeiro (Brasil), antecedendo ao workshop.

\section{O Serviço Social Brasileiro e os Limites da Atual Definição da FITS}

No Brasil, o Serviço Social nasceu ancorado em vertentes teórico-metodológicas neotomistas que, posteriormente, combinaram-se a perspectivas psicologizantes e estrutural funcionalistas, cujos princípios norteadores fragmentam a história, tratam os processos como fatos sociais isolados e responsabilizam os sujeitos individualmente pela sua condição socioeconômica. A perspectiva ao Serviço Social se resumia a buscar o desenvolvimento e o fortalecimento dos sujeitos individualmente, por meio de sua integração ao meio social, como forma de buscar o bem comum.

O Serviço Social brasileiro rompeu com tais perspectivas, fortalecido pelo movimento de reconceituação latino-americano em um primeiro momento e consolidado pelo seu histórico e particular processo de construção de um projeto ético-político profissional (Netto, 1999), a partir do final da década de 1970. Desde então, a profissão experienciou sólidas e profundas mudanças teórico-metodológicas e ético-políticas, que resultaram na regulamentação profissional, hoje consubstanciada na Lei n. 8.662/1993, no Código de Ética Profissional e Diretrizes Curriculares da ABEPSS. São os princípios e diretrizes resultantes e determinados por esse processo que orientam a formação e o trabalho profissional brasileiro e estabelecem as bases para a compreensão do que é o Serviço Social no Brasil (CFESS, 2010).

Não podemos conceber o Serviço Social brasileiro sem reafirmar os princípios que estão na base do atual Código de Ética, que completou dezoito anos em 2011: liberdade como valor ético central, defesa dos direitos humanos, da cidadania, da democracia, equidade e justiça social, respeito à diversidade, ao pluralismo e construção de uma nova ordem social, sem dominação e exploração, articulação com movimentos sociais, compromisso com a qualidade dos serviços prestados aos usuários, exercício do Serviço Social sem discriminar nem ser discriminado. Para o Conselho Federal de Serviço Social, uma definição mundial que não contempla o projeto ético-político profissional e as particularidades do trabalho social em cada país não pode ser considerada uma definição mundial ou universal de trabalho social.

A definição de trabalho social da Fits incorpora alguns desses princípios, mas também incorpora outros de natureza completamente distinta, que a tornam eclética. Uma vez que a FITS, como organização internacional que congrega trabalha- 
dores sociais dos cinco continentes do globo, considera necessário trabalhar com uma conceituação sintética e geral de Serviço Social no mundo, chama-se a atenção para os riscos e limites dessa tarefa num universo planetário demasiado heterogêneo do ponto de vista de trajetória histórica, de cultura, de regimes políticos, de realidades socioeconômicas não só diversas, mas, geralmente, desiguais.

Entende-se que uma definição mundial deve ser suficientemente genérica para respeitar as particularidades e historicidades de cada nação, sem ferir suas conquistas éticas, políticas e profissionais. Desse modo, cabe sinalizar, na atual definição da Fits, os elementos que dificultam seu reconhecimento como expressão do Serviço Social no mundo. O documento de definição de trabalho social da Fits é sintético, não apresenta elementos de reflexão ou fundamentação, e está estruturado em cinco itens, com um parágrafo cada um: DEFINIÇÃO, COMENTÁRIO, VALORES, TEORIA, PRÁTICA.

O item DEFINIÇÃO ressalta apenas o trabalho com indivíduos para assegurar o bem-estar e afirma que o "assistente social ou trabalhador social promove a mudança social, a resolução de problemas no contexto das relações humanas e a capacidade e empenho das pessoas na melhoria do bem-estar" (Fits, 2000). Afirma que o profisisonal adota teorias de comportamento humano e dos sistemas sociais e focaliza a sua intervenção no relacionamento das pessoas com o meio que as rodeia. Também sinaliza que os princípios de direitos humanos e justiça social são elementos fundamentais para o trabalho social. No item COMENTÁRIO, afirma-se que "os profissionais do trabalho social são agentes de mudança na sociedade e também na vida dos indivíduos, famílias e comunidades a quem o seu trabalho se dirige" (Fits, 2000).

Ora, sabemos que há mudanças que não implicam transformações sociais substantivas, capazes de alcançar um patamar civilizatório de grau mais elevado que o vigente. A que sentido de mudança a definição se refere? Além disso, grandes transformações societárias, de conteúdo ético-político e econômico-social superiores, não se delimitam como estratégia de uma categoria profissional, mas se inscrevem como um esforço processual de uma filosofia, de uma teoria crítica da história e como contributo de um pensamento social e de uma ação coletiva de grande força política. Desde a década de 1970, o Serviço Social brasileiro (e latino-americano) rompeu com a ideia do assistente social como agente de mudança, porque o agente de mudança é o próprio cidadão-usuário do trabalho social. Por outro lado, a resolução de problemas e conflitos, visada pelo trabalhador social, circunscreve-se para além das "relações humanas" tal como formuladas na década de 1960, abrangendo a totalidade das relações sociais, econômicas, étnicas, de gênero, de orientação sexual, entre outras. 
O item VALORES enfatiza valores como: humanismo, democracia, respeito pela igualdade, valor e dignidade de todos. E aponta que os objetivos do trabalho social se constroem em torno do desenvolvimento das capacidades humanas individuais:

Desde o seu início, há um século atrás, o trabalho social centrou a sua acção na resposta às necessidades das pessoas, bem como o desenvolvimento das capacidades do ser humano. Os direitos humanos e a justiça social motivam e legitimam a sua acção. Solidariamente com os mais desfavorecidos, visa mitigar a pobreza e liberar as pessoas vulneráveis e oprimidas, promovendo a sua inclusão social. Os valores subjacentes ao trabalho social constam de códigos de ética da profissão a nível nacional e internacional. (Fits, 2000, p. 1)

Compreende-se que a definição da FITS é valiosa quando afirma que são fundamentais para o trabalho social os princípios que orientam a defesa dos direitos humanos em sua perspectiva contemporânea, que ampliou o seu campo para novos direitos civis, políticos, sociais, étnicos e ambientais, bem como os de justiça social substantiva. O Serviço Social brasileiro reconhece os usuários como sujeitos de direitos e defende a ampliação dos direitos como uma mediação fundamental na mudança das condições de vida dos(as) trabalhadores(as). Sua defesa, contudo, não tem como perspectiva a integração social, o bem-estar e a melhoria social nos marcos do capitalismo. Conforme apontado no documento "Serviço Social e reflexões críticas sobre práticas terapêuticas", ${ }^{10}$

temos um projeto profissional que se articula a um projeto societário emancipatório, mas esta articulação exige um conjunto de mediações que potencializa a intervenção profissional (com abordagens que podem ser individuais, grupais, familiares ou coletivas) nas condições institucionais, considerando as complexas relações entre Estado e sociedade e os embates entre projetos societários. (CFESS, 2010, p. 11)

Os valores da liberdade e da emancipação humana ancoram a defesa dos direitos humanos como expressão da luta contra todas as formas de opressão e exploração.

O item TEORIA prioriza o conhecimento empírico, sem considerar a produção científica e de conhecimento, e estabelece que a fundamentação teórica do trabalho social se dá exclusivamente nas teorias do desenvolvimento humano e do compor-

10. O documento está disponível na página eletrônica do CFESS: <http://www.cfess.org.br/>. 
tamento, ou seja, aquelas de natureza eminentemente psicologizante ou fundadas numa sociologia empirista e de inspiração funcionalista-sistêmica:

A metodologia do trabalho social apoia-se num conjunto de conhecimentos empíricos e resultantes de investigação e de avaliação de experiências práticas, incluindo conhecimentos específicos, inerentes a determinantes contextos locais. O trabalho social tem em conta a complexidade das interacções entre os seres humanos e o meio que os rodeia e a capacidade destes, apesar de afectados por isso, de estarem preparados para as modificarem incluindo os factores de âmbito biopsicossocial. O exercício desta profissão apoia-se em teorias de desenvolvimento de comportamento humano e ainda de sistemas sociais para analisar situações complexas e proporcionar transformações a nível individual, organizacional, social e cultural. (Fits, 2000, p. 1)

Sem dúvida, há trabalhadores sociais que ainda balizam sua intervenção com base em teorias comportamentais e sistêmicas, pois se trata de uma das linhas metodológicas das ciências sociais que orienta o trabalho de psicólogos e ações da psicologia social. Contudo, é absolutamente fundamental escapar ao falso consenso de uma definição geral fundada na abordagem comportamental, funcional-sistêmica e individualizante, com ênfase nas capacidades (aqui com clara inspiração em Amartya Sen), por não ser a única abordagem sequer da psicologia e muito menos do Serviço Social no mundo. Conforme afirma o CFESS (2010) em documento citado anteriormente, as vertentes comportamentais que fundamentaram os primórdios da profissão foram superadas historicamente: "É certo que ações de teor psicologizante marcaram os primórdios da profissão. Mas é certo, igualmente, que nos afastamos substancialmente dessa vertente e que a realização de terapias não integram nem a fundamentação teórica contemporânea da profissão e nem suas diretivas legais" (CFESS, 2010, p. 5). Desde fins da década de 1970, o Serviço Social brasileiro incorporou um arcabouço teórico crítico que possibilitou à pesquisa e à intervenção profissional compreender as condições reais de vida dos(as) usuários(as) com quem trabalha em uma perspectiva de totalidade, como expressões da "questão social", cuja superação não se dará por intervenções tecnicistas no âmbito da sociologia organizacional nem da atuação comportamental. A defesa dos direitos humanos é uma luta constante contra todas as formas de violência, discriminação, opressão e exploração. Não se trata de defender os direitos como mecanismo de sobrevivência no capitalismo, mas como mediação fundamental na luta pela construção de uma nova ordem social.

Ao discorrer sobre a PRÁTICA, o documento da Fits reconhece a atuação no âmbito das políticas sociais e dos direitos, mas sua intencionalidade se restringe à garantia do bem-estar individual nos marcos do capitalismo, e sob uma perspectiva psicossocial: 
O trabalho social enfrenta as barreiras, desigualdades e injustiças existentes na sociedade. Actua em situações de crise e de emergência, mas também dá resposta aos problemas de natureza pessoal e social do dia a dia. Este tipo de trabalho utiliza uma variedade de práticas, técnicas e acções em consonância com a abordagem holística (integral) do ser humano e do ambiente que o rodeia. A variedade de intervenções do trabalho social passa desde processos de natureza psicossocial focalizados a nível individual até intervenções relacionadas com a política social, planejamento social e desenvolvimento social. As intervenções integram aconselhamento, acompanhamento de casos, trabalho de grupo, trabalho social de cariz pedagógico, tratamento e terapia familiares, bem como ajudar as pessoas a obter os bens e serviços disponíveis na comunidade. A sua intervenção inclui ainda a gestão de organismos, de serviços comunitários e envolvimento em acções político-sociais para influenciar a política social e o desenvolvimento económico. A intervenção holística do trabalho social é universal, mas as prioridades no seu exercício variam de país para país e de tempos a tempos, conforme as condições culturais, históricas e socioeconômicas existentes. (Fits, 2000, p. 1)

A intervenção profissional não se dissocia de seu arcabouço teórico-metodológico. Assim, quando discutimos ou realizamos as competências e atribuições profissionais, o fazemos orientados por valores ético-políticos. O CFESS já sinalizou em documento anterior:

Quando elaboramos estudos socioeconômicos e/ou quando fazemos orientação e acompanhamento social a indivíduos, grupos e famílias; quando realizamos assessoria, avaliação e implementação de políticas, programas e projetos sociais; quando nos inserimos em processos de mobilização social ou quando estamos exercendo o magistério, temos, diante de nós, usuários que vivenciam a violação e/ou não acesso aos direitos em sua vida cotidiana. Os sujeitos de direitos vivenciam as dramáticas consequências da barbárie. É desse movimento real, produzido no embate entre as classes sociais, e saturado de inúmeras determinações, que emana a necessidade histórica do Serviço Social. Tal formulação densa de consequências e exigências movimenta, no cotidiano profissional, a necessidade de apreender os usuários do Serviço Social situados numa condição objetiva e subjetiva de classe. (Cfess, 2010, p. 11)

Embora se questione uma definição mundial de Serviço Social, que contraria o princípio dialético da historicidade, mas considerando que essa posição não é hegemônica na Fits, entende-se que é nosso dever insistir no processo de revisão da atual definição, de modo a contemplar as diferentes possibilidades e construções históricas e teórico-políticas dos países-membros da Fits, ou então ser suficientemente genérica para não ferir as concepções hegemônicas em cada país. 
Enfim, a Fits deve ser um mundo — do trabalho social — onde caibam todos os mundos.

Recebido em 31/8/2011 - Aprovado em 5/9/2011

\section{Referências bibliográficas}

CFESS. Atribuições privativas do(a) assistente social em questão. Brasília, 2002.

Práticas terapêuticas no âmbito do serviço social: subsídios para aprofundamento do estudo. Brasília, 2008. Disponível em: $<$ http://www.cfess.org.br/praticas.php $>$. Acesso: 15 ago. 2011.

. Serviço Social e reflexões críticas sobre práticas terapêuticas. Brasília, 2010. Disponível em: $<\mathrm{http}: / / \mathrm{www}$. cfess.org.br/arquivos/doc_CFESS_Terapias_e_SS_2010.pdf $>$. Acesso: 15 ago. 2011.

FITS - Federação Internacional de Trabalho Social. Definição de trabalho social, 2000. (portuguese version). Disponível em: <http://www.ifsw.org/p38000411.html>. Acesso: 8 ago. 2011.

NETTO, José Paulo. A construção do projeto ético-político do serviço social frente à crise contemporânea. In: . Capacitação em serviço social e política social. Brasília: CEAD, 1999. p. 91-110. m.1. Crise contemporânea, questão social e serviço social. 


\title{
ANEXO 1 \\ Proposta do Conselho Federal de Serviço Social do \\ Brasil (CFESS) para definição de Serviço Social
}

\author{
20ํㅗㄹ Conferência Mundial de Serviço Social \\ Hong Kong, 10 de junho de 2010
}

O Conselho Federal de Serviço Social (CFESS), organização brasileira reconhecida pela Lei Federal n. 8.662/1993, foi criado em 1957 e conta hoje com aproximadamente 90 mil assistentes sociais. No processo de revisão da definição de Serviço Social, apresentamos a seguir uma contribuição ao debate, compreendendo que uma definição mundial deve ser ampla, de modo a contemplar as diferenças existentes e particularidades dos países.

Definição: o(a) assistente social ou trabalhador(a) social atua no âmbito das relações sociais, junto a indivíduos, grupos, famílias, comunidade e movimentos sociais, desenvolvendo ações que fortaleçam sua autonomia, participação e exercício de cidadania, com vistas à mudança nas suas condições de vida.

Os princípios de defesa dos direitos humanos e justiça social são elementos fundamentais para o trabalho social, com vistas à superação da desigualdade social e de situações de violência, opressão, pobreza, fome e desemprego.

Comentário: a formação do(a) assistente social está fundamentada em princípios que respeitam as diferenças e fortalecem as potencialidades dos sujeitos com os quais trabalha, sem discriminação de qualquer natureza. Para tanto o(a) profissional deve ter postura ética, competência teórica e habilitação técnica para desenvolver suas competências e atribuições articuladas a um conjunto de valores, teorias e práticas de defesa dos direitos humanos.

Valores: o trabalho social desenvolve-se a partir dos ideais da democracia e os direitos humanos motivam e legitimam a sua ação, e seus valores radicam no respeito à igualdade, liberdade, enfrentamento da desigualdade, participação, equidade, eliminação de todas as formas de preconceito, respeito à diversidade de cultura, etnia, pensamento, orientação sexual, correntes teórico-metodológicas e defesa de uma sociedade sem guerras, sem violência e sem opressão.

No trabalho profissional esses valores se concretizam no fortalecimento de instituições democráticas, no fortalecimento dos movimentos sociais, na defesa de políticas econômicas a serviço do crescimento e da redistribuição de renda, na proposição de direitos sociais amplos e universais; na garantia da formação profissional com qualidade. Os valores subjacentes ao trabalho social constam nos códigos de ética da profissão em nível nacional e internacional.

Teoria: a metodologia do trabalho social apoia-se num conjunto de conhecimentos teóricos e empíricos, resultantes de investigação e de socialização de experiências, incluin- 
do conhecimentos específicos, inerentes a determinados contextos locais, analisados numa perspectiva de totalidade. Para compreender a complexidade das relações sociais e as condições de vida dos usuários com os quais trabalha, o trabalho social incorpora teorias sociais e econômicas que lhe permitam analisar e intervir em situações complexas junto a indivíduos, grupos, famílias e comunidades.

Prática: O trabalho social enfrenta as barreiras, desigualdades e injustiças existentes na sociedade. Atua em situações de crise e de emergência. Trabalha na elaboração, execução de políticas e projetos sociais, presta orientação a indivíduos e grupos, planeja, organiza e administra benefícios sociais, assessora órgãos, empresas e movimentos sociais, realiza pesquisas e estudos socioeconômicos para acesso a benefícios e serviços sociais.

Para isso é necessário que o trabalhador seja um profissional propositivo, com sólida formação ética, capaz de informar sobre os direitos sociais e meios de acessá-los.

Estes profissionais atuam como assessores em processo administrativos e judiciais com realização de vistorias, perícias, avaliações, análise de documentos, estudos técnicos, coletas de dados e pesquisa. Elaboram pareceres, laudos, relatórios e estudos de casos. A sua intervenção inclui ainda a gestão de organismos, de serviços comunitários e envolvimento em ações político-sociais para influenciar a política social e o desenvolvimento econômico.

A intervenção do trabalho social é universal, mas as prioridades no seu exercício variam de país para país e de tempos a tempos, conforme as condições culturais, históricas e socioeconômicas existentes.

Conselho Federal de Serviço Social

"Gestão Atitude Crítica para Avançar na Luta" 


\section{ANEXO 2 \\ Texto preliminar para o workshop sobre a definição de trabalho social da FITS ${ }^{11}$}

A atual definição de Trabalho Social da Federação Internacional de Trabalhadores Sociais — Fits foi aprovada na assembleia realizada em Montreal/Canadá, em 2000. Essa definição, vigente há dez anos, não contou com a adesão de todos os países, a exemplo dos da América Latina, que não se viram representados. Essa situação gerou a necessidade de sua revisão, inserindo-se num debate mais amplo e profundo sobre o Serviço Social no mundo. Na assembleia da Fits em Montreal, a posição dos latino-americanos foi a de acumular mais discussão, com o objetivo de obter um consenso maior. Todavia a posição foi derrotada e a definição foi aprovada com a indicação de sua revisão em dez anos, ou seja, em 2010 .

A partir do resultado da assembleia da Fits em 2000, o Comitê Mercosul de Associações Profissionais de Serviço Social elaborou o documento Declaración sobre la definición del Trabajo Social aprobado por la Fits (Mar Del Plata/Argentina, dezembro, 2000), no qual expressou um posicionamento crítico sobre seu conteúdo e forma de elaboração.

Em 2006, a Fits e a Aiets constituíram um GT mundial com o objetivo de trabalhar na revisão e apresentar uma proposta na assembleia da Fits em Hong Kong em 2010, porém não houve a reelaboração da definição.

Durante a Conferência Mundial e a Assembleia da Fits ocorridas em Hong Kong, em 2010, com o intuito estratégico de provocar o debate, o CFESS, apoiado pelos representantes da América Latina e de outros países, apresentou uma proposta de mudança de texto na definição vigente. Como resultado desse processo, a assembleia aprovou a realização de um workshop no Brasil com o GT Mundial, para discutir a atual definição e encontrar pontos convergentes e que não firam os projetos profissionais dos países-membros da Fits.

O Brasil está em processo de articulação com os demais países e com a presidência regional da Fits para a América Latina e o Caribe para a organização do evento com previsão de realização para o primeiro semestre de 2012, antecedendo a Conferência Mundial de Estocolmo, que ocorrerá em meados de 2012.

Embora haja controvérsias sobre a formulação de uma definição universal de trabalho social, deve-se insistir no processo de revisão da atual definição, de modo a contemplar as diferentes possibilidades e construções históricas e teórico-políticas dos países-membros da Fits.

11. Elaborado pelo GT Ampliado - Definição Mundial de Serviço Social - CFESS (Portaria n. 13, de 31 de maio de 2011), reunido no Rio de Janeiro em 13 de agosto de 2011, com a participação da presidência regional da FITS para América Latina e Caribe. 


\section{Proposta do Conselho Federal de Serviço Social - CFESS}

Os impactos da mundialização, no âmbito do trabalho social, são reveladores da expansão e da radicalização das desigualdades sociais e econômicas, resultado dos padrões internacionais de desenvolvimento que vêm permitindo a existência concomitante da acumulação de riquezas e da pobreza, com manifestações diferenciadas nas várias regiões e países. As contradições oriundas desse processo vêm alimentando, no âmbito das modernas democracias, a luta em defesa dos direitos humanos e sociais e a formulação e execução de políticas públicas e medidas coletivas de enfrentamento às desigualdades e às discriminações de toda natureza e que reconfiguram o trabalho social. Este se inscreve na divisão social e técnica do trabalho como profissão e área de conhecimento reconhecidas social e institucionalmente.

Definição: $\mathrm{O}$ (a) trabalhador social ou assistente social atua no âmbito das relações entre os sujeitos sociais e, entre eles, o Estado. Desenvolve um conjunto de ações de caráter socioeducativo que incidem na reprodução material e social da vida, com indivíduos, grupos, famílias, comunidades e movimentos sociais numa perspectiva de transformação social. Essas ações visam: fortalecer a autonomia, a participação e o exercício da cidadania; capacitar, mobilizar e organizar os sujeitos, individual e coletivamente, garantindo o acesso a bens e serviços sociais; a defesa dos direitos humanos; a salvaguarda das condições socioambientais de existência; e a efetivação dos ideais da democracia e o respeito à diversidade humana. Os princípios de defesa dos direitos humanos e da justiça social são elementos fundamentais para o trabalho social, para que esse trabalho se realize com vistas a combater a desigualdade social e as situações de violência, de opressão, de pobreza, de fome e de desemprego.

Comentário: A formação do(a) trabalhador(a) social ou assistente social está fundamentada em princípios que respeitam as diferenças e fortalecem as potencialidades dos sujeitos com os quais trabalha, sem discriminação de qualquer natureza. Para tanto, o(a) profissional deve ter postura ética, competência teórica e habilitação técnica para desenvolver suas competências e atribuições articuladas a um conjunto de valores, teorias e práticas de defesa dos direitos humanos.

Valores: As ações profissionais têm por base valores e princípios éticos universais, ou seja, a defesa da liberdade, da igualdade, da justiça social e da cidadania tendo em vista a superação da opressão, da fome, da pobreza, do desemprego e das desigualdades e discriminações sociais. Guiadas por tais valores e no zelo de sua qualidade, as práticas objetivam: o fortalecimento das instituições democráticas, das políticas econômicas a serviço do crescimento e da redistribuição da renda e da riqueza, dos direitos sociais universais; a observância de normas internacionais dos direitos humanos com respeito à diversidade de cultura, etnia/raça, geração, pensamento, identidade e relações de gênero, orientação sexual, concepções teórico-metodológicas e defesa de uma sociedade sem guerras, violência e opressão; o apoio às ações sociais globais na defesa das condições socioambientais e da sustentabilidade do meio ambiente que contribuam no combate à pobreza, à fome e ao de- 
semprego; no apoio à população em situações especiais decorrentes de conflitos políticos, religiosos e militares.

Teoria: Para compreender as relações sociais e as condições de vida dos usuários, o trabalho social incorpora teorias sociais e econômicas que lhe permitam analisar e intervir na realidade com vistas à sua transformação. Assim, portanto, a metodologia do trabalho social fundamenta-se em um acervo de conhecimentos teóricos e de informações empíricas resultantes de pesquisa científica e da socialização de experiências que possibilitem uma leitura crítica do processo histórico numa perspectiva de totalidade, em seu movimento e em suas contradições; simultaneamente, permitam decifrar a inserção de indivíduos, grupos, famílias e coletividades no processo social, suscitando a compreensão de seus modos de vida e de trabalho e de suas reivindicações sociais.

Prática: O exercício profissional requer domínio teórico-metodológico, postura ética e habilitação técnica para desenvolver competências e habilidades técnico-operativas atinentes ao trabalho social, tais como: formular e executar políticas sociais em órgãos da administração pública, em empresas e em organizações da sociedade civil; elaborar, executar e avaliar planos, projetos e programas na área social; contribuir para viabilizar a participação dos usuários nas decisões institucionais; planejar, organizar e administrar benefícios e serviços sociais; realizar pesquisas que subsidiem a formulação de políticas e ações profissionais; prestar assessoria e consultoria a órgãos da administração pública, empresas privadas e movimentos sociais relacionados às políticas sociais e à garantia dos direitos humanos e sociais da coletividade; orientar a população na identificação de recursos para o atendimento e defesa dos seus direitos; realizar estudos socioeconômicos para a identificação de demandas e necessidades sociais; realizar visitas, perícias técnicas, laudos, informações e pareceres sobre matéria de Trabalho social; exercer funções de direção em organizações públicas e privadas na área; assumir o magistério em trabalho social e supervisionar estudantes estagiários. Para isso é necessário que o trabalhador social seja crítico e propositivo, com sólida formação acadêmico-profissional, contribuindo na promoção, proteção, restituição e exigibilidade dos direitos sociais e os meios de acessá-los.

\section{Conselho Federal de Serviço Social}

"Gestão Tempo de Luta e Resistência" 